\title{
Anesthesia Management in Congenital Heart \\ Surgery in a Patient with Liver Transplantation
} Nihat Çine $\mathbb{0}$

Çıkar Çatışması: Çıkar çatışmamız yoktur. Finansal Destek: Finansal destek yoktur. Hasta Onamı: Hasta onamı alınmamışır.
Conflict of Interest: We have no conflict of interest. Funding: No financial support.

Informed Consent: Patient consent was not obtained.

Cite as: Işıldak FU, Yavuz Y, Şavluk ÖF, Uslu U, Çine N. Karaciğer nakli yapılmış hastada konjenital kalp cerrahisinde anestezi yönetimi. GKDA Derg. 2021;27(3):223-5.

Öz

Karaciğer nakli uzun yıllardan beri erişkin ve çocuk hastalarda başarılı bir şekilde uygulanmaktadır. Nakil yapılan hastaların sağkalım oranları arttıkça komorbidite ve nontransplant cerrahisi oranları da artmaktadır. Ailesel hiperkolesterolemi nedeniyle 7 yaşında iken önce koroner arter baypas cerrahisi, ardından (3 ay sonra) canlıdan karaciğer nakil ameliyatı geçiren 20 yaşındaki erkek hastaya aort kapak darlığı nedeniyle aort kök genişletme ameliyatı ve aort kapak replasmanı planlandı. Bu çalışmamızda, daha önceden karaciğer nakli yapılan hastada anestezi uygulaması deneyimimiz sunulmuştur.

Anahtar kelimeler: Karaciğer nakli, konjenital kalp cerrahisi, anestezi

\section{ABSTRACT}

Liver transplantation has been successfully applied in adult and pediatric patients for many years. As the survival rates of transplanted patients increase, the rates of comorbidity and nontransplant surgery also increase. In our case aortic root expansion and aortic valve replacement operation due to aortic valve stenosis was planned to 20-year-old male patient, who had undergone coronary bypass surgery at the age of 7 because of familial hypercholesterolemia, followed by a living donor liver transplant (3 months later). The goal of this study is to present our anesthesia experience with a patient who had a liver transplant before.

Keywords: Liver transplantation, congenital heart surgery, anesthesia
Received/Geliş: 21.05.2021

Accepted/Kabul: 09.06.2021

Published Online/Online yayın: 02.09.2021

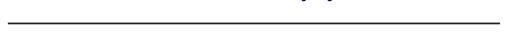

Fatma Ukil Işıldak Kartal Koşuyolu Yüksek ihtisas E.A.H Anesteziyoloji ve Reanimasyon Ana Bilim Dall, İstanbul, Türkiye ukilfatma@yahoo.com.tr ORCiD: 0000-0002-6080-7848

Y. Yavuz 0000-0003-0506-6474 ö.F. Şavluk 0000-0003-1875-1948

U. Uslu 0000-0002-4399-9606

N. Çine 0000-003-4805-3518

Kartal Koşuyolu Yüksek ihtisas E.A.H Anesteziyoloji ve Reanimasyon Ana Bilim Dalı, İstanbul 


\section{Giriş}

Karaciğer nakli uzun yıllardan beri başarılı bir şekilde uygulanmaktadır. Nakil yapılan hastaların sağkalım oranları arttıkça ek hastalıkların ve nontransplant cerrahisi oranlarında da artış olmaktadır. İleri dönemde gelişen kalp ve diğer sistem patolojileri nedeniyle cerrahi uygulamaları artmıştır. Karaciğer nakilli hastalarda koroner arter hastalığının görülme sıklığı artmaktadır. ${ }^{[1]} \mathrm{Bu}$ çalışmamızda, 13 yıl önce ailesel hiperkolesterolemi nedeniyle karaciğer nakil ameliyatı ve koroner baypas uygulanmış olan hastaya aort darlığı nedeni ile aort kök genişletme ve aort kapak replasmanı ameliyatında uyguladığımız anestezi yönetimimizi sunmayı amaçladık.

\section{OLGU SUNUMU}

Yirmi yaşında, erkek hasta $(175 \mathrm{~cm}, 55 \mathrm{~kg}), 13$ yıl önce ailesel hiperkolesterolemi nedeniyle 3 ay ara ile açık kalp ameliyatı (sol ana koroner arter-sol internal mamarian arter anastomuzu) ve karaciğer nakil ameliyatı yapıldığı öğrenildi. Hastanın yapılan fizik muayenesinde patoloji saptanmadı. Hastanın preoperatif hemogram, biyokimya ve kanama testleri normal sınırlardaydı. Preoperatif kolesterol değerleri normal sınırlardaydı. Ekokardiyografide ejeksiyon fraksiyonu \%70, aort kapağı biküspit ve kalın, aort kökü tubüler şekilde daralmış olarak izlendi. Orta derecede aort yetersizliği saptandı. Hastanın preoperatif dönemde yapılan koroner anjiyografisinde herhangi bir patoloji saptanmadı. Ameliyat sabahı premedikasyon için 2 $\mathrm{mg}$ iv midazolam yapıldı. Hasta ameliyat odasına alındı. Hastaya EKG, periferik oksijen satürasyonu $\left(\mathrm{SpO}_{2}\right)$, serebral near infrared spektroskopi (NIRS) ile monitorize edildi. 16G kanül ile periferik damar yolu açılarak invaziv arter monitorizasyonu (sağ radial arter) yapıldı. Kalp hızı 85/dk. (sinüs ritmi), TA 120/65 $\mathrm{mmHg}, \mathrm{SpO}_{2} \% 98$ olarak gözlendi. Anestezi indüksiyonunda $0.1 \mathrm{mg} / \mathrm{kg}$ midazolam, $1,5 \mathrm{mg} / \mathrm{kg}$ propofol, $5 \mu \mathrm{g} / \mathrm{kg}$ fentanil ve $0.6 \mathrm{mg} / \mathrm{kg}$ rokuronyum bromür kullanılarak 7,5 mm endotrakeal tüp ile entübe edildi. Sağ internal juguler vene santral venöz kateter takıldı. \% $60 \quad \mathrm{O}_{2}$-hava karışımı ile mekanik ventile edilen hastanın anestezi idamesi $0.25 \mu \mathrm{g} / \mathrm{kg} / \mathrm{dk}$. remifentanil infüzyonu, $8 \mu \mathrm{g} / \mathrm{kg} / \mathrm{dk}$ rokuronyum bromür infüzyonu ve $0.03 \mathrm{mg} / \mathrm{kg} / \mathrm{sa}$ midazolam ile sağlandı. Hastamıza $100 \mathrm{mg} / \mathrm{kg} /$ gün asist infüzyonu başlandı. Indüksiyon sonrası $250 \mathrm{mg}$ prednizolon intravenöz yapıldı. Ameliyat süresince ortalama arter basıncı $60 \mathrm{mmHg}$ üzerinde tutuldu. Hemodinamik açıdan bir sorun yaşanmadı. Hasta kardiyopulmoner baypastan $0,5 \mu \mathrm{g} / \mathrm{kg} / \mathrm{dk}$. milrinone, $0.03 \mu \mathrm{g} / \mathrm{kg} / \mathrm{dk}$. adrenalin inotrop destek ve $0,5 \mu \mathrm{g} / \mathrm{kg} / \mathrm{dk}$ nitrogliserin infüzyonu ile ayrıldı. Anestezi süresi $480 \mathrm{dk}$. kardiyopulmoner baypas süresi 283 dk., aortik kros klemp süresi $240 \mathrm{dk}$. olarak kaydedildi. İnotrop destek ile yoğun bakıma devredilen hasta postoperatif 15. saatte ekstübe edildi.

\section{TARTIŞMA}

Dünyada ilk karaciğer nakli (KC-N) 1963 yılında Thomas Starzl tarafından uygulanmıştır. Pediyatrik yaş grubunda da karaciğer nakli önemli bir yer tutmaktadır. Pediyatrik hastalarda karaciğer nakli, immünsüpresif ajanların kullanıma başlaması, cerrahi teknik ve deneyimlerdeki artış ile birlikte sağ kalım oranlarını arttırmıştır.

Karaciğer nakilli hastanın preoperatif değerlendirilmesi, diğer normal hastaların preoperatif değerlendirilmesinden bazı özellikler açısından farklıdır. Karaciğer nakilli hastanın preoperatif değerlendirilmesinde normal hastadan farklı olarak dikkate alınması gereken en önemli noktalar preoperatif greft fonksiyonu, immunosupresif ajan kullanımı, infeksiyon riski ve ameliyatın türüdür. Her hastada, kesinlikle iyi bir anamnez alınması ve fizik muayene yapılması şarttır. ${ }^{[2]}$ Bizim hastamız da preoperatif dönemde gastroenterolog tarafından greft fonksiyonları normal olarak değerlendirildi. Hastanın alınan immunsupresif ajan kullanmadığı öğrenildi.

Karaciğer nakilli hastalarda tüm anestezi ve analjezi yöntemleri kullanılabilir. Bu hastalarda eğer eritrosit transfüzyonu yapılacaksa hedef hemotokrit değeri hepatik arter stenozu riskini azaltmak için \%25-30 arasında tutulmaya çalışıımalıdır. Biz de hastamızda ameliyat süresince hemotokrit değerini \%25-30 aralığında olmasına dikkat ettik.

Küçük cerrahilerde EKG, $\mathrm{SpO}_{2}$, non-invaziv kan basın$\mathrm{Cl}$ gibi standart monitörizasyon teknikleri yeterlidir. Ancak, hastanın anamnezi, klinik durumu, planlanan cerrahi ve kanama beklentisi gibi durumlarda monitörizasyon genişletilmeli ve gerekiyorsa invaziv yöntemler kullanılmalıdır. Invaziv arteryel basınç 
takibi, santral venöz kateter, pulmoner arter kateteri (PAK) kardiyak problemi olanlarda, majör batın cerrahisi ameliyatlarında ve hemodinamik instabilite beklenen olgularda uygulanmalıdır. Standart monitorizasyona ek olarak, invaziv girişler yapılırken infeksiyon riski akıldan çıkarılmamalıdır. ${ }^{[2]}$

Karaciğer nakilli ve açık kalp cerrahisi uygulanacak hastalar için önemli olan bir diğer konu ise steroid stres dozunun uygulanıp uygulanmayacağına karar verilmesidir. Bu konuda kabul edilmiş ortak bir görüş birliği yoktur. Steroid dozu uygulanan ve uygulanmayan gruplar arasında yara yeri iyileşmesi ve infeksiyon açısından bir fark bulunmamıştır. ${ }^{[3]}$ Bu çalışmalar küçük olgu gruplarında yapılmıştır, daha sağlıklı bir değerlendirme için daha geniş olgu serilerine gereksinim vardır. Biz de kliniğimizde, antiinflamatuar olarak preoperatif prednizolon rutin olarak uyguluyoruz. Karaciğer nakil sonrası açık kalp cerrahisi uygulanan hastalarda karşılaşılan en önemli sorun karaciğer fonksiyonlarının bozulmasıdır. Deb ve ark. ${ }^{\left[{ }^{[4]}\right.}$ 13 karaciğer nakli yapılmış hastada açık kalp cerrahisi yapıldığını, bu hastaların 6'sında (\%46) postopratif erken dönemde geçici greft oklüzyonuna bağlı karaciğer enzimlerinde artış olduğunu ve taburculuk öncesinde hepsinin normal değerlerine döndüğünü bildirmişlerdir. ${ }^{[5]}$ Hastamızda da postoperatif 1. günde karaciğer fonksiyon testlerinde (KCFT) artış görüldü. $\mathrm{N}$-asetilsistein infüzyonuna devam edildi. Postoperatif 2. günden sonra KCFT de düşme görüldü.

Postoperatif dönemde yakın ve yoğun tıbbi takip gerektiren karaciğer nakli yapılmış hastalarda, normal kalp cerrahisi sonrası görülen atriyal fibrilasyon, akciğer ödemi, plevral efüzyon gibi komplikasyonların görüldüğü bildirilmektedir. ${ }^{[5]}$ Hastamızda bu tür komplikasyonlarla karşılaşmadık.

Sonuç olarak, yeterli sayıda olgu olmamasına rağmen, pediyatrik karaciğer nakli yapılmış hastalarda gerekli önlemler alınarak başarılı bir şekilde açık kalp cerrahisi uygulanabilmektedir. Bu hasta grubunda karaciğer fonksiyonlarının postoperatif erken dönemde yakın takip ve tedavisi gerekmektedir.

\section{KAYNAKÇA}

1. Teker ME, Teskin Ö. Karaciğer nakli yapılmış bir hastada açık kalp cerrahisi: Olgu sunumu. Arch Clin Exp Med. 2017;2(3):87-88. https://doi.org/10.25000/acem.330318

2. Hüseyin İlksen Toprak. Karaciğer transplantasyonlu hastada anestezi: Journal of Anesthesia 2013; 43-45

3. Cingöz F, Özerhan IH, Şahin MA, Yağcl G, Arslan M, Çetiner S. Karaciğer nakli yapılmış hastada açık kalp cerrahisi. Gülhane Tıp Dergisi 2012;54:165-7. https://doi.org/10.5455/gulhane.19518

4. Deb SD, Mullany CJ, Kamath PS, Dearani JA, Daly RC, Orszulak TA, Schaff HV. Cardiacsurgery in kidney and liver transplantpatients. Mayo ClinProc 2006;81:917-922. https://doi.org/10.4065/81.7.917

5. Ota T, Rocha R, Wei LM, Toyoda Y, Gleason TG, Bermudez C. Surgical outcomes after cardiac surgery in liver transplant recipients. Thorac Cardiovasc Surg 2013;145:1072-6. https://doi.org/10.1016/j.jtcvs.2012.09.099 